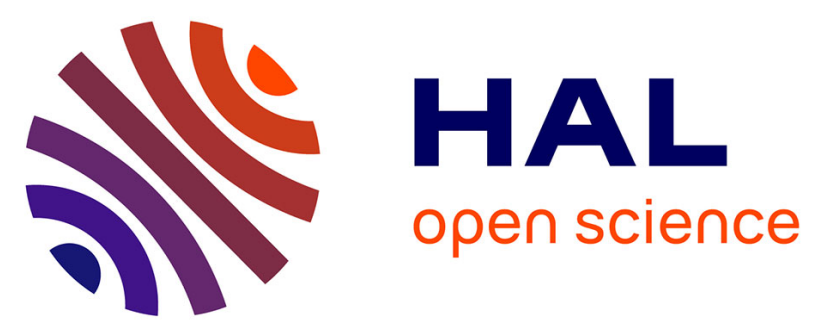

\title{
Theoretical investigation of the spin crossover transition states of the addition of methane to a series of Group 6 metallocenes using minimum energy crossing points
} Jennifer Green, Jeremy Harvey, Rinaldo Poli

\section{- To cite this version:}

Jennifer Green, Jeremy Harvey, Rinaldo Poli. Theoretical investigation of the spin crossover transition states of the addition of methane to a series of Group 6 metallocenes using minimum energy crossing points. Journal of the Chemical Society Dalton Transactions, 2002, 8, pp.1861-1866. 10.1039/B111257K . hal-03284388

\section{HAL Id: hal-03284388 \\ https://hal.science/hal-03284388}

Submitted on 20 Jul 2021

HAL is a multi-disciplinary open access archive for the deposit and dissemination of scientific research documents, whether they are published or not. The documents may come from teaching and research institutions in France or abroad, or from public or private research centers.
L'archive ouverte pluridisciplinaire HAL, est destinée au dépôt et à la diffusion de documents scientifiques de niveau recherche, publiés ou non, émanant des établissements d'enseignement et de recherche français ou étrangers, des laboratoires publics ou privés. 
Theoretical investigation of the spin crossover transition states of the addition of methane to a series of Group 6 metallocenes using minimum energy crossing points.

Jennifer C. Green ${ }^{\mathrm{a}}$, Jeremy N. Harvey ${ }^{\mathrm{b}}$ and Rinaldo Poli ${ }^{\mathrm{c}}$

${ }^{a}$ Inorganic Chemistry Laboratory, South Parks Road, Oxford OX1 3QR, UK

${ }^{b}$ University of Bristol, School of Chemistry, Cantock's Close, Bristol BS8 1TS, UK,

${ }^{c}$ Laboratoire de Synthèse et d'Electrosynthèse Organométalliques, Université de

Bourgogne, Faculté de Science Gabriel, 6 boulevard Gabriel, 21000 Dijon, France

Corresponding author: Prof. J. C. Green

Tel: 01865272637

Fax: 01865272690

E-mail: jennifer.green@chem.ox.ac.uk 


\begin{abstract}
Density functional calculations are reported on the addition of methane to group 6 metallocenes, $\mathrm{M}\left(\eta-\mathrm{C}_{5} \mathrm{H}_{5}\right)_{2}(\mathbf{M}), \mathrm{M}\left(\mathrm{CH}_{2}\left(\eta-\mathrm{C}_{5} \mathrm{H}_{4}\right)_{2}\right)(\boldsymbol{a}-\mathbf{M})$ and $\mathrm{M}\left(\eta-\mathrm{C}_{5} \mathrm{Me}_{5}\right)_{2}\left(\mathbf{M}^{*}\right)$ where $\mathrm{M}=\mathrm{Mo}$ and $\mathrm{W}$. Full geometry optimisations were carried out on the singlet and triplet 16 electron complexes, ${ }^{1}[\mathrm{M}$ and $\left.{ }^{3}[\mathrm{M}]\right]$, the $\eta^{2}$-methane complexes, ${ }^{1}\left[\mathrm{M}\left(\eta^{2}-\mathrm{CH}_{4}\right)\right]$, and the hydridomethyl adducts, ${ }^{1}\left[\mathrm{M}\left(\mathrm{CH}_{3}\right)(\mathrm{H})\right]$. The triplet state for $[\mathrm{M}]$ was found to be more stable for all six metallocenes, the difference being least in the case of the ansa-bridged system. Formation of the hydridomethyl comples was exoenergetic for all tungsten systems and for a-Mo, the other two Mo systems being endoenergetic. Minumum energy crossing points between the triplet and singlet surfaces were calculated for Mo, $\mathbf{W}$, a-W and $\mathbf{W}^{*}$. These MECP formed the barrier to formation of the methane complex. Transition states for insertion of $\mathrm{M}$ into the $\mathrm{C}-\mathrm{H}$ bond and exchange between the coordinated $\mathrm{H}$ of the methane complex were also calculated for Mo, W, a-W and $\mathbf{W}^{*}$. For $\mathbf{W}$ and $\mathbf{W}^{*}$ these were of similar height to the MECP. For aW the insertion barrier was lower than the MECP while for Mo it was higher. Activation of methane was established as being most favourable for a-W. The calculated results are fully in accord with published experimental data on hydrogen exchange in and thermal stablity of ${ }^{1}\left[\mathrm{M}\left(\mathrm{CH}_{3}\right)(\mathrm{H})\right]$ where $\mathrm{M}$ $=\mathbf{W}, \mathbf{a}-\mathbf{W}$ and $\mathbf{W}$.
\end{abstract}




\section{Introduction}

Common reactions of late transition metals are oxidative addition and its reverse, reductive elimination, where the oxidised metal is a $\mathrm{d}^{6} 18$ electron species and the reduced metal a $\mathrm{d}^{8} 16$ electron species. For late transition metals both classes of compounds are stable diamagnetic molecules. When the oxidative addition happens in a concerted manner the reaction proceeds on a singlet surface and is readily amenable to theoretical modelling. For early transition metals with fewer d electrons, the reduced metal complex will often have a paramagnetic ground state and the oxidised complex, with an 18 electron configuration, will be diamagnetic. In these cases the reaction will involve a cross-over between a triplet surface and a singlet one.

Techniques for locating the mimimum energy crossing point (MECP) between different spin surfaces have been successfully employed in studying organometallic reactions. ${ }^{1-4}$ In this work we use them to elucidate the transition states involved in the reaction of methane with a series of unbridged and ansa-bridged group 6 metallocenes.

The group $6 \mathrm{~d}^{4}$ metallocenes have 16 electron triplet ground states. In the case of $\mathrm{Cr}$ the metallocene, though oxygen sensitive, is thermally stable in a wide variety of solvents and no report is available, to the best of our knowledge, of oxidative additions to this molecule to afford stable $\mathrm{Cr}(\mathrm{IV})$ derivatives. In contrast, the metallocenes of Mo and $\mathrm{W}$ are reactive intermediates, readily undergoing oxidative addition reactions to give $\mathrm{d}^{2} 18$ electron metallocene derivatives. Among the reactions that have been demonstrated is the activation of $\mathrm{C}-\mathrm{H}$ bonds.

Experimental studies of thermal stability of alkyl hydrides give information on the pathways for alkane activation, which is the reverse of reductive elimination of alkanes. The three metallocene systems which have been most thoroughly studied, $\left(\mathrm{C}_{5} \mathrm{H}_{5}\right)_{2} \mathrm{~W}(\mathrm{H})\left(\mathrm{CH}_{3}\right),{ }^{5-7}\left(\mathrm{C}_{5} \mathrm{Me}_{5}\right)_{2} \mathrm{~W}(\mathrm{H})\left(\mathrm{CH}_{3}\right)^{8}$ and $\mathrm{CMe}_{2}\left(\mathrm{C}_{5} \mathrm{H}_{4}\right)_{2} \mathrm{~W}(\mathrm{H})\left(\mathrm{CH}_{3}\right)^{9}, 10$ show significant differences in their thermal stability. The unbridged methyl hydrides decompose over the range $40-100^{\circ} \mathrm{C}$ eliminating methane, whereas the ansa-bridged compound is thermally stable up to $120^{\circ} \mathrm{C}$. Thus there is a strong indication that the reactivity of the bare metallocenes are also likely to differ and that the ansa-bridged metallocene is likely to activate C$\mathrm{H}$ bonds more readily than the others.

Density functional studies on exchange and elimination reactions of $\left(\mathrm{C}_{5} \mathrm{H}_{5}\right)_{2} \mathrm{~W}(\mathrm{H})\left(\mathrm{CH}_{3}\right)$ and $\mathrm{CH}_{2}\left(\mathrm{C}_{5} \mathrm{H}_{4}\right)_{2} \mathrm{~W}(\mathrm{H})\left(\mathrm{CH}_{3}\right)$ demonstrated that this was likely to be the case. ${ }^{11}$ Elimination occurred via a 
singlet methane $\sigma$-complex which released methane by crossing to a repulsive triplet surface. The stability of the ansa-bridged methyl hydride was shown to be due to the high energy of the triplet metallocene product compared with the unbridged analogue, which has a parallel ring structure. The ansa-bridge prevents the relaxation of the rings to the parallel geometry and consequently the $\mathrm{d}$ electrons are destabilized. Thus the ansa-bridged metallocene will be the more reactive of the two 16 electron intermediates. A subsequent study on a wider range of metallocenes gave similar computational results but focussed on the singlet surface when discussing barrier heights to oxidative addition. $^{12}$

It seemed to us worthwhile to take advantage of MECP techniques to identify the singlet-triplet crossing point on the pathway to formation of the methane $\sigma$-complex in order to compare the reactivity of these group 6 metallocene species as $\mathrm{C}-\mathrm{H}$ activating species. Consequently we have studied six systems based on the metallocenes $\mathrm{M}\left(\eta-\mathrm{C}_{5} \mathrm{H}_{5}\right)_{2}(\mathbf{M}), \mathrm{M}\left(\mathrm{CH}_{2}\left(\eta-\mathrm{C}_{5} \mathrm{H}_{4}\right)_{2}\right)(\boldsymbol{a}-\mathbf{M})$ and $\mathrm{M}(\eta-$ $\left.\mathrm{C}_{5} \mathrm{Me}_{5}\right)_{2}\left(\mathbf{M}^{*}\right)$ where $\mathrm{M}=\mathrm{Mo}$ and $\mathrm{W}$.

\section{Computational Details}

All computations have been carried out using the well-established B3LYP hybrid density functional level of theory, as implemented in the Gaussian $98^{13}$ and Jaguar $4.0^{14}$ program packages. Most of the Gaussian calculations used the LanL2DZ ECP and double-zeta basis set on the W and Mo atoms, together with the associated all-electron double-zeta basis sets on carbon and hydrogen (this level of theory is simply referred to as "LanL2DZ" henceforth). Some computations were repeated using a similar basis including polarization functions. Specifically, the LanL2DZ ECP and basis were retained on the metal atoms, but the standard $6-31 \mathrm{G}^{* *}$ basis was used on $\mathrm{C}$ and $\mathrm{H}$ (referred to as "6$31 \mathrm{G}^{* *}$ " henceforth). Jaguar calculations were performed for the $\left[\left(\mathrm{Cp}^{*}\right)_{2} \mathrm{~W}\left(\mathrm{CH}_{4}\right)\right]$ system, using the standard LACVP basis on all atoms; this uses the LanL2DZ basis on the metal atoms, and the unpolarised 6-31G basis on $\mathrm{C}$ and $\mathrm{H}$ (referred to as "LACVP"). As expected for such similar procedures, for the stationary points where both methods were used for this system, Gaussian LanL2DZ and Jaguar LACVP computations gave essentially identical results. In fact, throughout this project, the $6-31 \mathrm{G}^{* *}$ results were very similar to those obtained with the unpolarised LanL2DZ basis, suggesting that in this particular case, at least, reliable results can be obtained using a modestly sized 
basis. All structures were fully optimised, with the optimisation of the MECPs being carried out by a combination of Gaussian or Jaguar and the shell script/Fortran code of one of the authors. ${ }^{15,} 16$ Geometry optimisations without symmetry constraints, backed up in several cases by computation of vibrational frequencies, showed all structures studied here to have at least $\mathrm{C}_{\mathrm{S}}$ symmetry, with some belonging to higher point groups. Accordingly, the MECP optimisations were carried out within $\mathrm{C}_{\mathrm{S}}$ symmetry. Standard cut-offs were applied in Gaussian, whereas the tightest DFT and pseudospectral grids were used throughout in Jaguar. The reported energies do not include a correction for zero-point energy as frequency calculations were not possible in all cases, due to computational restrictions for the larger $\mathrm{Cp}^{*}$ systems.

\section{Results}

Full geometry optimisations for each system (Mo, W, $\boldsymbol{a}$-Mo, $\boldsymbol{a}-\mathbf{W}, \mathbf{M o} *$ and $\left.\mathbf{W}^{*}\right)$, globally abbreviated as M, were carried out on the following stationary points: the singlet and triplet 16-electron complexes, ${ }^{1}[\mathrm{M}]$ and ${ }^{3}[\mathrm{M}]$; the MECP on the way to the formation of the $\eta^{2}$-methane complex, ${ }^{1,3}\left[\mathrm{M}\left(\eta^{2}-\mathrm{H}-\mathrm{CH}_{3}\right)\right]$; the singlet $\eta^{2}$-methane complex, ${ }^{1}\left[\mathrm{M}\left(\eta^{2}-\mathrm{H}-\mathrm{CH}_{3}\right)\right]$; the final oxidative addition product, ${ }^{1}\left[\mathrm{M}(\mathrm{H})\left(\mathrm{CH}_{3}\right)\right]$; and the two transition states (TS) leading from the $\eta^{2}$-methane complex to the oxidative addition product on one side, ${ }^{1}\left[\mathrm{M}\left(\mathrm{H}---\mathrm{CH}_{3}\right)\right]$ ins. TS, and to the exchange between the agostic and non agostic hydrogen atoms, ${ }^{1}\left[\mathrm{M}\left(\mathrm{H}-\mathrm{CH}_{2}-\mathrm{H}\right)\right]$ exch. TS, on the other side. The energy results are listed in Table 1 for the simple metallocene systems (Mo and W), in Table 2 for the ansa systems ( $\boldsymbol{a}$ Mo and $\boldsymbol{a}-\mathbf{W})$, and in Table 3 for the decamethylmetallocene systems (Mo* and $\left.\mathbf{W}^{*}\right)$. Note that not all stationary points have been located for the experimentally less relevant molybdenum systems. In addition, Figure 1, Figure 2, and Figure 3 provide a visual summary of all relative energies (except the TS for the exchange process) for the $\mathrm{Cp}$, ansa, and $\mathrm{Cp}^{*}$ systems, respectively. The relevant structural parameters for each optimised molecule are collected in Table 4.

<insert Table 1, Table 2, Table 3, Table 4, Figure 1, Figure 2, and Figure3 here> 


\section{Discussion}

Some of the stationary points on the potential energy surfaces for the methane oxidative addition to the metallocene and ansa-metallocene systems have already been discussed elsewhere. ${ }^{11,12}$ The decamethylmetallocene systems, reported here for the first time, allow a direct comparison between the $\mathrm{Cp}$ and $\mathrm{Cp}^{*}$ systems as well as a calibration of the computational method against the experimentally available parameters.

It is to be noted that, where both are available, the LanL2DZ results obtained with Gaussian and the LACVP ones from Jaguar are extremely similar from the points of view of both energies and geometries (see Table 1and Table 4). As a general trend, the metal-ring centroid ( M-Cnt) distances are slightly longer at the LANL2DZ or LACVP levels than at the $6-31 \mathrm{G}^{* *}$ level, while the opposite is true for the metal- $\mathrm{CH}_{3}$ distances. The metal- $\mathrm{H}$ and the $\mathrm{CH}_{3}-\mathrm{H}$ distances are essentially identical at all levels. The bond angles are also essentially independent of the computational level.

\section{${ }^{3}[\mathrm{M}]$ and ${ }^{1}[\mathrm{M}]$}

The 16-electron bis(cyclopentadienyl) complexes were computed in two spin states, singlet and triplet. The triplet is more stable than the singlet for all systems investigated here, as experimentally established for Mo and $\mathbf{W} \cdot{ }^{17}$ For the non ansa complexes, the triplet has a "linear" structure around the metal, with nearly parallel cyclopentadienyl rings. In contrast, the higher-lying singlet has a bent structure, with a Cnt-M-Cnt' angle in the $149-159^{\circ}$ range, lower for the Mo species than the corresponding $\mathrm{W}$ species. This angle is greater for the $\mathrm{Cp}^{*}$ systems $\left(156.9-158.9^{\circ}\right)$ than for the $\mathrm{Cp}$ systems (149.5-152.6 ${ }^{\circ}$, undoubtedly for steric reasons. The M-Cnt distance is systematically longer by ca. $0.08 \AA$ in the triplet species. Two factors are in operation here. In a bent metallocene the highest half-occupied orbital in the triplet structure, $4 \mathrm{a}_{1}$, is metal-ring antibonding, so its occupancy lengthens the metal-ring distance. Also it has been generally noted that, with the same spin state, bending a metallocene reduces the average M-C distance as more of the metal d-orbitals are available for bonding the ring in the lower symmetry. ${ }^{18}$ The ansa systems, on the other hand, are constrained by the ansa bridge to adopt a bent structure with the Cnt-M-Cnt' angle in the narrow $130-133^{\circ}$ range, this being essentially independent of the metal and marginally greater for the triplet than for the singlet. Consequently, the triplet state is considerably destabilised yielding a smaller gap to the excited singlet 
state $(35-41 \mathrm{~kJ} / \mathrm{mol})$ than for the $\mathrm{Cp}$ or $\mathrm{Cp}^{*}$ systems $(80-104 \mathrm{~kJ} / \mathrm{mol})$. These gaps are slightly higher, but the trends are identical, relative to previous calculations on the same molecules. ${ }^{11,12}$

\section{${ }^{1}\left[\mathrm{M}\left(\eta^{2}-\mathrm{H}-\mathrm{CH}_{3}\right)\right]$}

The next stationary point is the singlet complex with methane, which we find to have an $\eta^{2}$, asymmetric, $\mathrm{C}_{\mathrm{S}}$ structure for all systems, in which one $\mathrm{C}-\mathrm{H}$ bond complexes the metal in the equatorial plane of symmetry. The agostic $\mathrm{C}-\mathrm{H}$ bond is significantly longer than the other methane $\mathrm{C}-\mathrm{H}$ bonds (average $1.088 \AA$ ) and this lengthening is greater for the W systems (1.138-1.156 $⿱$ ) than for those of Mo (1.122-1.126 ̊) indicating a stronger interaction for the former. This is confirmed by the significantly shorter $\mathrm{M} \cdots \mathrm{H}$ distance for $\mathrm{W}$ (by ca. $0.09 \AA$ for each metallocene system; $c f$. a corresponding shortening of ca. $0.03 \AA$ for the $\mathrm{M}$-Cnt distance). The $\mathrm{M} \cdots \mathrm{CH}_{3}$ distance is correspondingly shorter by $0.1 \AA$ for a W system compared to the corresponding Mo system. The M$\eta^{2}-\left(\mathrm{H}-\mathrm{CH}_{3}\right)$ interaction bends the metallocene unit further relative to the corresponding singlet metallocene precursor and slightly lengthens the M-Cnt bonds. These effects are most pronounced for the bulkier $\mathrm{Cp}^{*}$ systems and least for the more rigid ansa systems.

The energy of this point is higher than ${ }^{3}[\mathrm{M}]+\mathrm{CH}_{4}$ but lower than ${ }^{1}[\mathrm{M}]+\mathrm{CH}_{4}$ for the $\mathrm{Cp}$ and the ansa systems. For the permethylated $\mathrm{Cp}^{*}$ complexes, the steric repulsion towards the incoming methane moiety displaces the $\eta^{2}$ complex up in energy, so that it is now actually less stable than the separated singlet fragments. As a result, there is now a small barrier for the addition of methane to the 16-electron precursor even when this is in its singlet excited state. It is noteworthy in this context that the product of thermal decomposition of ${ }^{1}\left[\mathbf{W}^{*}\left(\mathrm{CH}_{3}\right)(\mathrm{H})\right]$ is the tucked-in compound $\mathrm{Cp} * \mathrm{~W}\left(\eta^{1} \mathrm{CH}_{2}-\right.$ $\left.\eta^{5} \mathrm{C}_{5} \mathrm{Me}_{4}\right)(\mathrm{H})$, where the $\mathrm{W}$ has activated one of the $\mathrm{C}-\mathrm{H}$ bonds of a methyl substituent. ${ }^{8} \mathrm{We}$ calculate this structure to lie at $-31.3 \mathrm{~kJ}$ mol-1 relative to ${ }^{3}\left[\mathbf{W}^{*}\right]$; there is presumably a barrier to insertion due to the large geometry changes.

\section{${ }^{1}\left[\mathbf{M}(\mathbf{H})\left(\mathbf{C H}_{3}\right)\right]$}

Oxidative addition of the methane $\mathrm{C}-\mathrm{H}$ bond leads to the last stationary point, the 18-electron hydridomethyl product. This is also characterised by $\mathrm{C}_{\mathrm{s}}$ symmetry, the hydridic $\mathrm{H}$ and methyl $\mathrm{C}$ atoms lying in the bisecting plane of the (ring) ${ }_{2} \mathrm{M}$ moiety, symmetrically disposed on either side of the CntM-Cnt' plane. The $\mathrm{M}-\mathrm{H}$ and $\mathrm{M}-\mathrm{CH}_{3}$ distances are essentially identical for all systems (in the narrow 1.67-1.71 $\AA$ and 2.22-2.25 $\AA$ ranges, respectively) and the same is true for the $\mathrm{H}-\mathrm{M}-\mathrm{CH}_{3}$ angles, these being marginally smaller for the Mo $\left(74.9-75.6^{\circ}\right)$ than for the $\mathrm{W}\left(76.4-77.0^{\circ}\right)$ systems. The Cnt-M-Cnt 
angles remain essentially unchanged relative to the corresponding agostic intermediate, while the MCnt distances are lengthened by ca. $0.05 \AA$ during the oxidative addition process.

The overall oxidative addition process (from ${ }^{3}[\mathrm{M}]+\mathrm{CH}_{4}$ to ${ }^{1}\left[\mathrm{M}(\mathrm{H})\left(\mathrm{CH}_{3}\right)\right]$ ), is calculated as more exoenergetic (for the $\mathbf{W}, \boldsymbol{a}$-Mo and $\boldsymbol{a}-\mathbf{W}$ systems) or less endoenergetic (for the Mo system) with respect to both previous studies. For the $\mathrm{W}$ systems formation of the methyl hydride is substantially more exoenergetic for a-W than either $\mathbf{W}$ or $\mathbf{W}^{*}$. For the Mo systems it is only exoenergetic for the ansa-bridged a-Mo. Thus, thermodynamically, addition of methane to a group 6 metallocene is favoured for the ansa-bridged systems and more so for W than Mo.

\section{${ }^{1,3}\left[\mathrm{M}\left(\eta^{2}-\mathrm{H}-\mathrm{CH}_{3}\right)\right] \mathrm{MECP}$}

The highest point leading from the triplet 16-electron metallocenes to the $\eta^{2}$-methane complexes is the minimum-energy crossing point (MECP). This point is the only truly novel "stationary" point reported here, albeit a crucial one, and lies slightly higher in energy than the $\eta^{2}$ complex. The MECP is of $\mathrm{C}_{\mathrm{S}}$ symmetry and resembles the $\eta^{2}$ singlet complex, but with longer $\mathrm{M} \cdots \mathrm{H}$ and $\mathrm{M} \cdots \mathrm{C}$ distances. The interaction between the "agostic" C-H bond and the metal centre is already felt at this level, as this bond is already slightly lengthened relative to the free $\mathrm{CH}_{4}$ molecule. For a- $\mathbf{W}$ the methane is significantly further from the metal than is the case in the unbridged species.

The height of the MECP above ${ }^{3}[\mathrm{M}]+\mathrm{CH}_{4}$ gives an indication of the activation barrier to formation of the methane complex. For the series the order is a-W $<<\mathbf{W}<\mathbf{M o}<\mathbf{W}^{*}$. Thus the ansabridged tungsten metallocene is expected to be kinetically the most likely candidate to activate methane.

The energy difference, corresponding to the barrier to methane dissociation from the $\eta^{2}$ complex, is much higher for the ansa systems relative to the $\mathrm{Cp}$ and $\mathrm{Cp} *$ systems, in line with the greater thermal stability of the ansa ${ }^{1}\left[\mathbf{M}(\mathrm{H})\left(\mathrm{CH}_{3}\right)\right]$ products. The later MECP for methane dissociation is a result of the higher energy triplet state for the ansa-bridged species. The triplet involves occupancy of the high energy $4 a_{1}$ orbital of the geometry constrained bent metallocene. ${ }^{18}$

The energetic properties of the MECP are rather similar to those previously deduced from a partial optimisation study, in which the geometry was constrained to the $C_{2 V}$ point group, and the W-C bond length was systematically varied on both potential energy surfaces. ${ }^{11}$ This fairly good performance of the partial optimisation method suggests that the singlet and triplet surfaces have a fairly similar energetic behaviour along all coordinates except the $\mathrm{W}-\mathrm{C}$ distance. Also, the fact that 
restricting the search to $C_{2 V}$ geometries did not have a major effect on the quality of the results confirms that the surfaces are very flat.

\section{${ }^{1}\left[\mathrm{M}\left(\mathrm{H}---\mathrm{CH}_{3}\right)\right]$ ins. TS}

The TS leading from the $\eta^{2}$-methane complexes to the oxidative addition products is a regular first order saddle point on the singlet potential energy surface, its geometry being also, like that of the MECP, very close to that of the $\mathrm{M}\left(\eta^{2}-\mathrm{H}-\mathrm{CH}_{3}\right)$ minimum. This point also lies, like the MECP, only slightly higher in energy than the $\eta^{2}$ complex. Both $\mathrm{M} \cdots \mathrm{H}$ and $\mathrm{M} \cdots \mathrm{CH}_{3}$ separations are strongly decreased in each system relative to the corresponding $\eta^{2}$-methane complex. They are closer to the corresponding distances in the final oxidative addition product. The $\mathrm{H}^{\cdots} \mathrm{CH}_{3}$ separation is correspondingly stretched quite significantly. These three distances are quite well correlated with each other and indicate that the insertion TS is more "late" for the Mo system than for any of the W system. Within the latter ones, it is more "late" for $\mathbf{W}^{*}$ than for $\mathbf{W}$, whereas the $\boldsymbol{a}-\mathbf{W}$ system has the most "early" insertion TS amongst all the systems investigated here.

The insertion TS barrier is always quite small for the tungsten systems and larger for the molybdenum systems, an expected consequence of the smaller exothermicity of the insertion step for the molybdenum systems. Relative to ${ }^{3}[\mathrm{M}]+\mathrm{CH}_{4} \mathbf{W}$ and $\mathbf{W}^{*}$ have an ins. TS very similar in energy to their MECP. For a-W the ins. TS is significantly lower than the MECP. Thus for the ansa-bridged W species the kinetic energy barrier to methane activation will be controlled by the singlet triplet crossing barrier to formation of the methane complex.

A comparison between the MECP and insertion TS energies shows that the molybdenum intermediates are more in favour of $\mathrm{CH}_{4}$ dissociation.

\section{${ }^{1}\left[\mathrm{M}\left(\mathrm{H}-\mathrm{CH}_{2}-\mathrm{H}\right)\right]$ exch. TS}

In addition to methane dissociation and oxidative addition, the $\eta^{2}-\mathrm{CH}_{4}$ intermediate is also able to undergo exchange of the hydridic $\mathrm{H}$ atom with one of the methyl $\mathrm{H}$ atoms via an $\eta^{3}$ structure with two $\mathrm{C}-\mathrm{H}$ bonds interacting with the metal. The two exchanging $\mathrm{C}-\mathrm{H}$ bonds interact with the metal centre less strongly, as expected, then the single agostic bond in the $\eta^{2}$-methane complex as shown by the longer M-C and shorter $\mathrm{C}-\mathrm{H}$ distances. The $\mathrm{M}-\mathrm{H}$ distances, on the other hand, are equivalent or even slightly shorter in the exchange TS. This structure was found to be an extremely low-lying, $C_{2 V^{-}}$ symmetric, transition state for all systems. The calculated imaginary frequencies are very small (e.g. 28 and $114 \mathrm{~cm}^{-1}$, respectively, for the $\mathbf{M o}$ and $\mathbf{W}$ cases. Previous studies suggested this point to be 
instead a second-order saddle-point; ${ }^{11}$ it is clear that with such a flat potential energy surface, small differences in computational methods will inevitably lead to a slightly different topology in this region. The main point is that hydrogen exchange should be facile.

The barrier to this exchange process from the methane complex is particularly low for the Mo and $\mathbf{W}$ systems and lower relative to both the $\mathrm{CH}_{4}$ elimination and oxidative addition processes.

\section{Comparison with experiment.}

No example of a molybdenocene methyl hydride has been isolated. Our calculations suggest that only $\left[\mathrm{a}-\mathrm{Mo}\left(\mathrm{CH}_{3}(\mathrm{H})\right]\right.$ would possibly be stable but insolubility of the parent $\left[\mathrm{a}-\mathrm{MoCl}_{2}\right]$ led to less of its chemistry being developed than the analogous tungsten system. ${ }^{10}$ We thus confine our experimental comparisons to the tungsten results.

Study of the rates of hydrogen exchange and alkane elimination of tungstenocene methyl hydrides has provided quantitative data on the activation parameters for the $\mathbf{W}$ and $\mathbf{W}^{*}$ systems. Though an exact comparison between free energies and enthalpies of activation and the energy barriers calculated here is not legitimate, it is reasonable to expect that the calculated energy barriers to a large extent determine the relative magnitudes of the experimentally observed kinetic parameters.

Norton and co-workers have obtained values of $\Delta \mathrm{G}^{+}$of $106 \mathrm{~kJ} / \mathrm{mol}$ for the hydrogen exchange reaction and $110 \mathrm{~kJ} / \mathrm{mol}$ for the methane elimination reaction of $\left[\mathbf{W}\left(\mathrm{CH}_{3}\right)(\mathrm{H})\right] \cdot{ }^{7}$ Parkin and Bercaw obtain a $\Delta \mathrm{H}^{\ddagger}$ of $122.6 \mathrm{~kJ} / \mathrm{mol}$ for the elimination of $\mathrm{C}_{6} \mathrm{H}_{5} \mathrm{CH}_{3}$ from $\left[\mathbf{W}^{*}\left(\mathrm{CH}_{2} \mathrm{C}_{6} \mathrm{H}_{5}\right)(\mathrm{H})\right]$ and demonstrate that elimination of $\mathrm{CH}_{4}$ from $\left[\mathbf{W}^{*}\left(\mathrm{CH}_{3}\right)(\mathrm{H})\right]$ proceeds at a similar rate, more slowly than elimination from $\left[\mathbf{W}\left(\mathrm{CH}_{3}\right)(\mathrm{H})\right]{ }^{8}$

Our calculations suggest that, from the viewpoint of $\left[\mathrm{M}\left(\mathrm{CH}_{3}\right)(\mathrm{H})\right]$, in the case of $\mathbf{W}$ and $\mathbf{W}^{*}$ the highest energy barrier to both exchange and elimination is that to formation of the methane complex. The value is $121.3 \mathrm{~kJ} / \mathrm{mol}$ for $\mathbf{W}$ and $\sim 134 \mathrm{~kJ} / \mathrm{mol}$ for $\mathbf{W}^{*}$, in good agreement with experimental values both as to magnitude and trend. Once a methane complex is formed, the barrier to elimination is less than that to reinsertion. For $\mathbf{W}$ the barrier to exchange is very small but for $\mathbf{W}^{*}$ the exchange barrier is comparable to that of reinsertion.

Studies by Green et al. on $\left[\mathrm{a}-\mathrm{W}\left(\mathrm{CH}_{3}\right)(\mathrm{H})\right]$ show a hydrogen scrambling rate an order of magnitude lower than that found for $\left[\mathbf{W}\left(\mathrm{CH}_{3}\right)(\mathrm{H})\right]$, but activation parameters are not reported. Also elimination from [a-W( $\left.\left(\mathrm{CH}_{3}\right)(\mathrm{H})\right]$ did not occur up to a temperature of $120^{\circ} \mathrm{C}$. In this case we calculate the energy barrier to exchange as $136.8 \mathrm{~kJ} / \mathrm{mol}$, in line with the lower rate, and that to elimination as 
$148.9 \mathrm{~kJ} / \mathrm{mol}$. On formation of the methane complex the barrier to reinsertion is $4.4 \mathrm{~kJ} / \mathrm{mol}$, that to exchange is $5.2 \mathrm{~kJ} / \mathrm{mol}$ and that to elimination $17.3 \mathrm{~kJ} / \mathrm{mol}$. Thus the unusual thermal stability of [a$\left.\mathbf{W}\left(\mathrm{CH}_{3}\right)(\mathrm{H})\right]$ is accounted for.

\section{Comparison with previous calculations}

Previous DF calculations using the ADF code, Becke and Perdew functionals and Slater type orbitals gave a similar structures for the $\mathbf{W}$ and a-W systems to those described above. ${ }^{11}$ The energy profile was also similar though actual values differed somewhat.

Calculations using the Gaussian code (B3LYP/LANL2DZ) have been reported on a wider variety of metallocenes including the Mo, a-Mo, W and a-W systems. ${ }^{12}$ Though a closer correspondence might be expected with the current work for this method, there are some discrepancies in structures; for $\mathrm{M}\left(\mathrm{CH}_{3}\right)(\mathrm{H})$ the methyl group is shown apparently to lie in the Cnt-M-Cnt' plane rather than to one side of it. The relative energies are grossly similar but differ in value. For example, the value obtained for the singlet-triplet splitting in a-W is $21.6 \mathrm{~kJ} / \mathrm{mol}$ compared with our value of $35.4 \mathrm{~kJ} / \mathrm{mol}$ with an apparently similar procedure. The authors find, as we do, for all $[\mathrm{M}]$ that the triplets are lower in energy than the singlets, and that the difference is least for a-W.

However, the major difference between this work and that of $\mathrm{Su}$ and $\mathrm{Chu}$ lies in the interpretation of the results. In discussing the activation of methane they focus on the singlet surface. The activation barrier they consider is that of insertion relative to ${ }^{1}[\mathrm{M}]+\mathrm{CH}_{4}$. Thus they reach the opposite conclusion to ours, namely that $\mathbf{W}$ is more likely to activate methane than a-W. If in each case their triplet-singlet excitation energy is added to their estimate of the activation barrier this order is reversed, with the value of $80 \mathrm{~kJ} / \mathrm{mol}$ for the $\mathbf{W}$ system and $39 \mathrm{~kJ} / \mathrm{mol}$ for the a-W system. Our value for $\mathbf{W}$ is similar at $75.3 \mathrm{~kJ} / \mathrm{mol}$. However for the a-W system we estimate that it is the MECP that is the highest barrier to methane activation and that that lies $27 \mathrm{~kJ} / \mathrm{mol}$ above ${ }^{3}[\mathrm{a}-\mathbf{W}]+\mathrm{CH}_{4}$. The true triplet ground state of the metallocene intermediate should not be ignored. In all cases the bulk of the activation energy is in the formation of the singlet methane complex from the triplet ground state.

\section{Conclusions}

Reaction of methane with a group 6 metallocene is calculated to proceed from the ground state triplet metallocene, via a minimum energy crossing point to a singlet surface and a methane complex. Insertion into the $\mathrm{C}-\mathrm{H}$ bond to form the methyl hydride product proceeds through a further transition 
state. Formation of the methyl hydride is exoenergetic for all the tungsten systems studied but for the molybdenum systems only the ansa-bridged [a-Mo $\left.\left(\mathrm{CH}_{3}\right)(\mathrm{H})\right]$ forms exoenergetically.

For $\mathbf{W}$ and $\mathbf{W}^{*}$ the two barriers are of comparable height whereas for a-W the MECP lies higher than the barrier to insertion. For Mo the barrier to insertion is higher than the MECP. The overall barrier to methane activation is in the order $\mathrm{a}-\mathbf{W}<\mathbf{W}<\mathbf{W}^{*}$ and the reaction energy in the order a-W $>\mathbf{W}>\mathbf{W}^{*}$. Both the orders are largely determined by the triplet-singlet excitation energy which is least in the ansa-bridged system and greatest in the permethylated system. The low value for a-W may be attributed to the destabilisation of the $4 a_{1}$ orbital on bending the metallocene; this orbital is unoccupied in the singlet state but occupied in the triplet state.

\section{Acknowledgements}

RP is grateful to CINES for a grant of free CPU time. JNH thanks the EPSRC (GR/M92089) for financial support.

\section{References}

$1 \quad$ K. M. Smith, R. Poli, and J. N. Harvey, New J. Chem., 2000, 24, 77.

2 K. M. Smith, R. Poli, and J. N. Harvey, Chem. Eur. J., 2001, 7, 1679.

3 J. N. Harvey, Journal of the American Chemical Society, 2000, 122, 12401.

4 J. N. Harvey, in 'Spin-Forbidden Reactions in Transition-Metal Chemistry', ed. T. R. Cundari, 2001.

5 N. J. Cooper, M. L. H. Green, and R. Mahtab, J. Chem. Soc. Dalton Trans., 1979, 1557.

6 R. M. Bullock, C. E. L. Headford, S. E. Kegley, and J. R. Norton, J. Am. Chem. Soc., 1985, 107, 727 .

R. M. Bullock, C. E. L. Headford, K. M. Hennessy, S. E. Kegley, and J. R. Norton, J. Am. Chem. Soc., 1989, 111, 3897.

$8 \quad$ G. Parkin and J. E. Bercaw, Organometallics, 1989, 8, 1172.

9 L. Labella, A. Chernega, and M. L. H. Green, J.Chem. Soc. Dalton Trans., 1995, 395.

10 A. Chernega, J. Cook, M. L. H. Green, L. Labella, S. J. Simpson, J. Souter, and A. H. H. Stephens, J. Chem. Soc. Dalton Trans., 1997, 3225.

11 J. C. Green and C. N. Jardine, J. Chem. Soc. Dalton Trans., 1998, 1057.

12 M.-D. Su and S.-Y. Chu, J. Phys. Chem. A, 2001, 105, 3591.

13 M. J. Frisch, G. W. Trucks, H. B. Schlegel, G. E. Scuseria, M. A. Robb, J. R. Cheeseman, V. G. Zakrzewski, J. Montgomery, J. A., R. E. Stratmann, J. C. Burant, S. Dapprich, J. M. Millam, A. D. Daniels, K. N. Kudin, M. C. Strain, O. Farkas, J. Tomasi, V. Barone, M. Cossi, R. Cammi, B. Mennucci, C. Pomelli, C. Adamo, S. Clifford, J. Ochterski, G. A. Petersson, P. Y. Ayala, Q. Cui, K. Morokuma, D. K. Malick, A. D. Rabuck, K. Raghavachari, J. B. 
Foresman, J. Cioslowski, J. V. Ortiz, A. G. Baboul, B. B. Stefanov, G. Liu, A. Liashenko, P. Piskorz, I. Komaromi, R. Gomperts, R. L. Martin, D. J. Fox, T. Keith, M. A. Al-Laham, C. Y. Peng, A. Nanayakkara, C. Gonzalez, M. Challacombe, P. M. W. Gill, B. Johnson, W. Chen, M. W. Wong, J. L. Andres, C. Gonzalez, M. Head-Gordon, E. S. Replogle, and J. A. Pople, 'Gaussian 98, Revision A.7', Gaussian, Inc., 1998.

14 in 'Jaguar', Portland, OR, 1991-2000.

15 J. N. Harvey, M. Aschi, H. Schwarz, and W. Koch, Theor. Chem. Acc., 1998, 99, 95.

16 J. N. Harvey and M. Aschi, Phys. Chem. Chem. Phys., 1999, 1, 5555.

17 P. A. Cox, P. Grebenik, R. N. Perutz, M. D. Robinson, R. Grinter, and D. R. Stern, Inorg. Chem., 1983, 22, 3614.

18 J. C. Green, Chem. Soc. Rev., 1998, 263-271, 263. 
Table 1. Energies $\left(\mathrm{kJ} \mathrm{mol}^{-1}\right)$ relative to ${ }^{3}[\mathrm{M}]+\mathrm{CH}_{4}$ of various points on the relevant singlet and triplet potential energy surfaces for the metallocene systems.

\begin{tabular}{c|cr|rr}
\hline & \multicolumn{2}{|c|}{$\mathrm{M}=\mathrm{Cp}_{2} \mathrm{Mo}$} & \multicolumn{2}{c}{$\mathrm{M}=\mathrm{Cp}_{2} \mathrm{~W}$} \\
& LanL2DZ & $6-31 \mathrm{G}^{* *}$ & LanL2DZ & $6-31 \mathrm{G}^{* *}$ \\
\hline${ }^{1}[\mathrm{M}]+\mathrm{CH}_{4}$ & 100.9 & 96.1 & 79.8 & 81.9 \\
${ }^{3}[\mathrm{M}]+\mathrm{CH}_{4}$ & 0.0 & 0.0 & 0.0 & 0.0 \\
${ }^{1}\left[\mathrm{M}\left(\eta^{2}-\mathrm{H}-\mathrm{CH}_{3}\right)\right]$ & 86.7 & 80.5 & 65.5 & 64.9 \\
${ }^{1,3}\left[\mathrm{M}\left(\eta^{2}-\mathrm{H}-\mathrm{CH}_{3}\right)\right] \mathrm{MECP}$ & 91.0 & $/$ & 74.6 & $/$ \\
${ }^{1}\left[\mathrm{M}\left(\mathrm{H}-\mathrm{CH}-\mathrm{H}_{2}\right)\right]$ exch. TS & 86.9 & $/$ & 66.2 & $/$ \\
${ }^{1}\left[\mathrm{M}\left(\mathrm{H}---\mathrm{CH}_{3}\right)\right]$ ins. TS & 117.7 & $/$ & 75.3 & $/$ \\
${ }^{1}\left[\mathrm{M}(\mathrm{H})\left(\mathrm{CH}_{3}\right)\right]$ & 40.8 & 34.2 & -46.0 & -45.0 \\
\hline
\end{tabular}


Table 2. Energies $(\mathrm{kJ} / \mathrm{mol})$ relative to ${ }^{3}[\mathrm{M}]+\mathrm{CH}_{4}$ of various points on the relevant singlet and triplet potential energy surfaces for the ansa-metallocene systems.

\begin{tabular}{|c|c|c|c|c|}
\hline & \multicolumn{2}{|c|}{$\mathrm{M}=\mathrm{CH}_{2}\left(\mathrm{C}_{5} \mathrm{H}_{4}\right)_{2} \mathrm{Mo}$} & \multicolumn{2}{|c|}{$\mathrm{M}=\mathrm{CH}_{2}\left(\mathrm{C}_{5} \mathrm{H}_{4}\right)_{2} \mathrm{~W}$} \\
\hline & LanL2DZ & $6-31 \mathrm{G}^{* *}$ & LanL2DZ & $6-31 \mathrm{G}^{* *}$ \\
\hline${ }^{1}[\mathrm{M}]+\mathrm{CH}_{4}$ & 40.6 & 33.9 & 35.4 & 33.4 \\
\hline${ }^{3}[\mathrm{M}]+\mathrm{CH}_{4}$ & 0.0 & 0.0 & 0.0 & 0.0 \\
\hline${ }^{1}\left[\mathrm{M}\left(\eta^{2}-\mathrm{H}-\mathrm{CH}_{3}\right)\right]$ & 21.9 & 13.4 & 9.7 & 4.5 \\
\hline${ }^{1,3}\left[\mathrm{M}\left(\eta^{2}-\mathrm{H}-\mathrm{CH}_{3}\right)\right] \mathrm{MECP}$ & I & I & 27.0 & I \\
\hline${ }^{1}\left[\mathrm{M}\left(\mathrm{H}-\mathrm{CH}_{2}-\mathrm{H}\right)\right]$ exch. TS & / & / & 14.9 & / \\
\hline${ }^{1}\left[\mathrm{M}\left(\mathrm{H}---\mathrm{CH}_{3}\right)\right]$ ins. TS & l & / & 14.1 & l \\
\hline${ }^{1}\left[\mathrm{M}(\mathrm{H})\left(\mathrm{CH}_{3}\right)\right]$ & -35.3 & -41.8 & -121.9 & -123.3 \\
\hline
\end{tabular}


Table 3. Energies $(\mathrm{kJ} / \mathrm{mol})$ relative to ${ }^{3}[\mathrm{M}]+\mathrm{CH}_{4}$ of various points on the relevant singlet and triplet potential energy surfaces for the decamethylmetallocene systems.

\begin{tabular}{c|rr|rrr}
\hline & \multicolumn{2}{|c|}{$\mathrm{M}=\mathrm{Cp}_{2}{ }_{2} \mathrm{Mo}$} & \multicolumn{3}{c}{$\mathrm{M}=\mathrm{Cp}_{2}{ }_{2} \mathrm{~W}$} \\
& LanL2DZ & $6-31 \mathrm{G}^{* *}$ & LanL2DZ & LACVP & $6-31 \mathrm{G}^{* *}$ \\
\hline${ }^{1}[\mathrm{M}]+\mathrm{CH}_{4}$ & 102.3 & 95.4 & 96.2 & 94.5 & 87.9 \\
${ }^{3}[\mathrm{M}]+\mathrm{CH}_{4}$ & 0.0 & 0.0 & 0.0 & 0.0 & 0.0 \\
${ }^{1}[\mathrm{M}]+\mathrm{CH}_{4}$ add. TS & $/$ & $/$ & $/$ & 105.2 & $/$ \\
${ }^{1}\left[\mathrm{M}\left(\eta^{2}-\mathrm{H}-\mathrm{CH}_{3}\right)\right]$ & 111.4 & 107.5 & $/$ & 101.8 & 99.5 \\
${ }^{1,3}\left[\mathrm{M}\left(\eta^{2}-\mathrm{H}-\mathrm{CH}_{3}\right)\right] \mathrm{MECP}$ & $/$ & $/$ & $/$ & 104.4 & $/$ \\
${ }^{1}\left[\mathrm{M}\left(\mathrm{H}_{-}-\mathrm{CH}_{2}-\mathrm{H}\right)\right]$ exch. TS & $/$ & $/$ & $/$ & 108.0 & $/$ \\
${ }^{1}\left[\mathrm{M}\left(\mathrm{H}---\mathrm{CH}_{3}\right)\right]$ ins. TS & $/$ & $/$ & $/$ & $\mathrm{Ca} .108 .{ }^{(\mathrm{a})}$ & $/$ \\
${ }^{1}\left[\mathrm{M}(\mathrm{H})\left(\mathrm{CH}_{3}\right)\right]$ & 53.4 & 51.9 & -21.4 & -25.7 & -19.2 \\
\hline
\end{tabular}

(a) It was not possible to fully optimise the geometry of this TS. The energy shown was obtained as a rough maximum from a sequence of partial geometry optimisations at various fixed $\mathrm{W}-\mathrm{C}$ distances. 
Table 4. Selected structural parameters (distances in $\AA$; angles in ${ }^{\circ}$ ) for all optimized structures. ${ }^{\text {a }}$

\begin{tabular}{|c|c|c|c|c|c|c|}
\hline & $\mathrm{M}-\mathrm{Cnt}^{\mathrm{a}}$ & M-H & $\mathrm{M}-\mathrm{CH}_{3}$ & $\mathrm{H}-\mathrm{CH}_{3}$ & Cnt-M-Cnt'a & $\mathrm{H}-\mathrm{M}-\mathrm{CH}_{3}$ \\
\hline $\bar{~}{ }^{1}$ Mo & 1.950 & & & & 149.49 & \\
\hline${ }^{3}$ Mo & 2.028 & & & & 176.95 & \\
\hline${ }^{1} \mathbf{M o}\left(\eta^{2}-\mathrm{H}-\mathrm{CH}_{3}\right)$ & 1.977 & 2.215 & 2.842 & 1.122 & 146.10 & 21.37 \\
\hline${ }^{1,3} \mathbf{M o}\left(\eta^{2}-\mathrm{H}-\mathrm{CH}_{3}\right) \mathrm{MECP}$ & 1.969 & 2.497 & 3.183 & 1.108 & 147.93 & 17.75 \\
\hline${ }^{1} \mathbf{M o}\left(\mathrm{H}-\mathrm{CH}_{2}-\mathrm{H}\right)$ exch. TS & 1.977 & 2.409 & 2.831 & 1.109 & 145.94 & 22.64 \\
\hline${ }^{1} \mathbf{M o}\left(\mathrm{H}---\mathrm{CH}_{3}\right)$ ins. TS & 2.008 & 1.742 & 2.427 & 1.429 & 146.77 & 35.52 \\
\hline${ }^{1} \mathbf{M o}(\mathrm{H})\left(\mathrm{CH}_{3}\right)$ & 2.034 & 1.676 & 2.253 & & 146.11 & 74.89 \\
\hline${ }^{1} a$-Mo & 1.940 & & & & 130.29 & \\
\hline${ }^{3} a$-Mo & 2.012 & & & & 132.55 & \\
\hline${ }^{1} \boldsymbol{a}-\mathbf{M o}\left(\eta^{2}-\mathrm{H}-\mathrm{CH}_{3}\right)$ & 1.955 & 2.162 & 2.867 & 1.126 & 129.45 & 20.32 \\
\hline${ }^{1} \boldsymbol{a}-\mathrm{Mo}(\mathrm{H})\left(\mathrm{CH}_{3}\right)$ & 2.008 & 1.696 & 2.224 & & 128.26 & 75.47 \\
\hline${ }^{1} \mathbf{M o}^{*}$ & 1.964 & & & & 156.91 & \\
\hline${ }^{3} \mathbf{M o}^{*}$ & 2.026 & & & & 177.21 & \\
\hline${ }^{1} \mathbf{M o} *\left(\eta^{2}-\mathrm{H}-\mathrm{CH}_{3}\right)$ & 2.008 & 2.200 & 2.981 & 1.122 & 150.52 & 18.10 \\
\hline${ }^{1} \mathbf{M o} *(\mathrm{H})\left(\mathrm{CH}_{3}\right)$ & 2.072 & 1.671 & 2.249 & & 149.55 & 75.56 \\
\hline${ }^{1} \mathbf{W}$ & 1.916 & & & & 152.60 & \\
\hline${ }^{3} \mathbf{W}$ & 1.995 & & & & 179.51 & \\
\hline${ }^{1} \mathbf{W}\left(\eta^{2}-\mathrm{H}-\mathrm{CH}_{3}\right)$ & 1.948 & 2.120 & 2.752 & 1.138 & 146.51 & 22.59 \\
\hline${ }^{1,3} \mathbf{W}\left(\eta^{2}-\mathrm{H}-\mathrm{CH}_{3}\right) \mathrm{MECP}$ & 1.943 & 2.542 & 3.231 & 1.107 & 150.45 & 17.39 \\
\hline${ }^{1} \mathbf{W}\left(\mathrm{H}-\mathrm{CH}_{2}-\mathrm{H}\right)$ exch. TS & 1.948 & 2.332 & 2.738 & 1.115 & 146.40 & 23.72 \\
\hline${ }^{1} \mathbf{W}\left(\mathrm{H}---\mathrm{CH}_{3}\right)$ ins. TS & 1.970 & 1.803 & 2.489 & 1.323 & 146.60 & 30.95 \\
\hline${ }^{1} \mathbf{W}(\mathrm{H})\left(\mathrm{CH}_{3}\right)$ & 2.016 & 1.693 & 2.244 & & 147.47 & 76.65 \\
\hline${ }^{1} a-W$ & 1.906 & & & & 131.44 & \\
\hline${ }^{3} a-W$ & 1.968 & & & & 132.48 & \\
\hline${ }^{1} \boldsymbol{a}-\mathbf{W}\left(\eta^{2}-\mathrm{H}-\mathrm{CH}_{3}\right)$ & 1.927 & 2.022 & 2.729 & 1.156 & 130.13 & 22.44 \\
\hline${ }^{1,3} \boldsymbol{a}-\mathbf{W}\left(\eta^{2}-\mathrm{H}-\mathrm{CH}_{3}\right) \mathrm{MECP}$ & 1.926 & 2.786 & 3.487 & 1.103 & 131.38 & 15.71 \\
\hline${ }^{1} \boldsymbol{a}-\mathbf{W}\left(\mathrm{H}-\mathrm{CH}_{2}-\mathrm{H}\right)$ exch. TS & 1.924 & 2.393 & 2.818 & 1.111 & 130.07 & 22.79 \\
\hline${ }^{1} \boldsymbol{a}-\mathbf{W}\left(\mathrm{H}---\mathrm{CH}_{3}\right)$ ins. TS & 1.943 & 1.823 & 2.502 & 1.287 & 129.78 & 29.67 \\
\hline${ }^{1} \boldsymbol{a}-\mathbf{W}(\mathrm{H})\left(\mathrm{CH}_{3}\right)$ & 1.993 & 1.709 & 2.218 & & 128.36 & 76.98 \\
\hline${ }^{1} \mathbf{W} * \mathbf{c}$ & $(1.928)$ & & & & $(158.86)$ & \\
\hline${ }^{3} \mathbf{W}^{* \mathrm{c}}$ & $\begin{array}{c}1.991 \\
(1.989)\end{array}$ & & & & $\begin{array}{c}177.35 \\
(177.37)\end{array}$ & \\
\hline${ }^{1} \mathbf{W}^{*}\left(\eta^{2}-\mathrm{H}-\mathrm{CH}_{3}\right)^{\mathrm{c}}$ & (1.980) & $(2.040)$ & $(2.797)$ & $(1.150)$ & $(150.51)$ & (20.87) \\
\hline $1,3 \mathbf{W}^{*}\left(\eta^{2}-\mathrm{H}-\mathrm{CH}_{3}\right) \mathrm{MECP}^{\mathrm{c}}$ & $(1.956)$ & $(2.352)$ & $(3.168)$ & (1.116) & $(150.96)$ & $(16.05)$ \\
\hline${ }^{1} \mathbf{W}^{*}\left(\mathrm{H}-\mathrm{CH}_{2}-\mathrm{H}\right)$ exch. $\mathrm{TS}^{\mathrm{c}}$ & $(1.976)$ & $(2.398)$ & $(2.838)$ & $(1.110)$ & $(150.54)$ & $(22.54)$ \\
\hline${ }^{1} \mathbf{W}^{*}\left(\mathrm{H}---\mathrm{CH}_{3}\right)$ ins. $\mathrm{TS}^{\mathrm{c}}$ & $(2.000)$ & $(1.780)$ & $(2.510)$ & (1.344) & $(150.25)$ & $(30.97)$ \\
\hline${ }^{1} \mathbf{W}^{*}(\mathrm{H})\left(\mathrm{CH}_{3}\right)^{\mathrm{c}}$ & $\begin{array}{c}2.052 \\
(2.048)\end{array}$ & $\begin{array}{c}1.686 \\
(1.687)\end{array}$ & $\begin{array}{c}2.242 \\
(2.248)\end{array}$ & & $\begin{array}{c}149.62 \\
(149.54)\end{array}$ & $\begin{array}{c}76.39 \\
(76.03)\end{array}$ \\
\hline
\end{tabular}

${ }^{a}$ All parameters are from the B3LYP/LANL2DZ calculations, unless otherwise stated. The calculated 6-31G** geometries are available as Supporting Information. ${ }^{\mathrm{b}} \mathrm{Cnt}$ and $\mathrm{Cnt}$ ' are the cyclopentadienyl ring centroids. ${ }^{c}$ Values in parentheses are from calculations at the B3LYP/LACVP level.. 


\section{Figure Captions}

Figure 1. Reaction coordinate for the $\mathrm{CH}_{4}$ oxidative addition to the metallocenes of molybdenum and tungsten. All energies are at the B3LYP/LANL2DZ level.

Figure 2. Reaction coordinate for the $\mathrm{CH}_{4}$ oxidative addition to the ansa-metallocenes of molybdenum and tungsten. All energies are at the B3LYP/LANL2DZ level.

Figure 3. Reaction coordinate for the $\mathrm{CH}_{4}$ oxidative addition to the decamethylmetallocenes of molybdenum and tungsten. Energies are at the B3LYP/6-31G** level for the Mo* system and at the B3LYP/LACVP level for the $\mathbf{W}^{*}$ system. 
Figure 1

(a) Mo

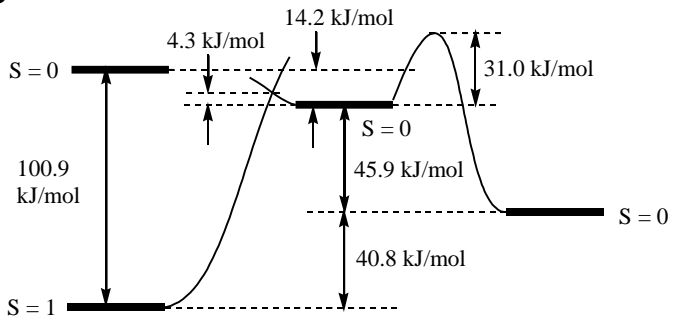

(b) W

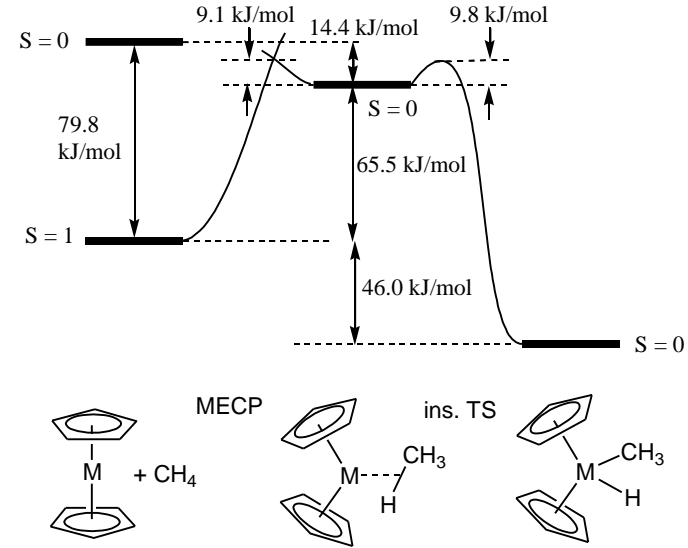


Figure 2

(a) a-Mo

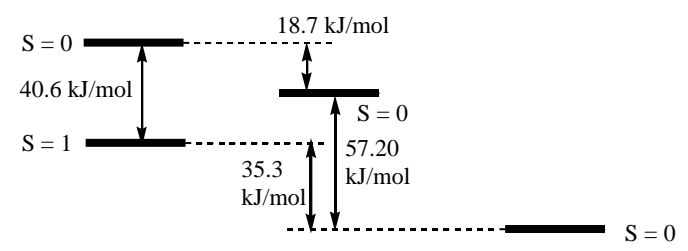

(b) $a-W$

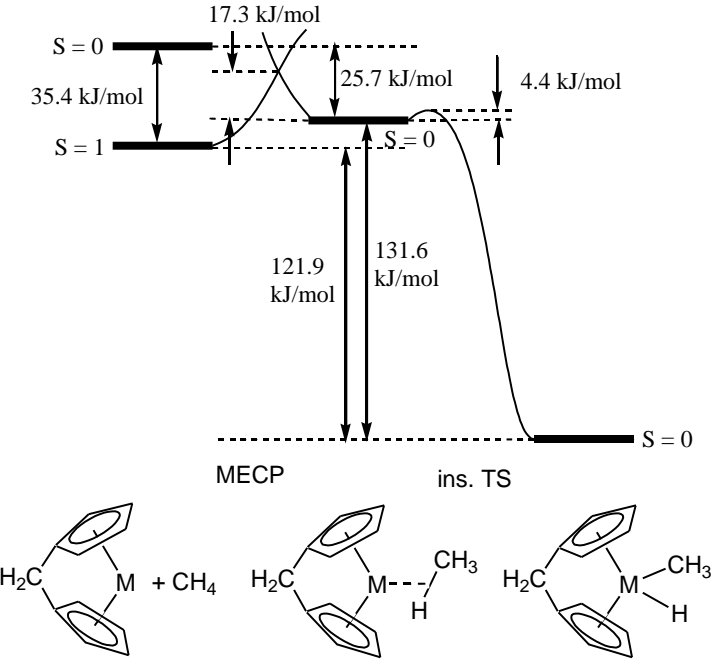


Figure 3

(a) Mo*

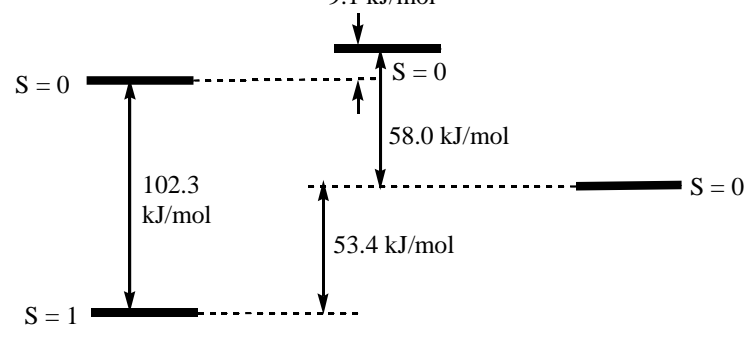

$\begin{array}{lllll}\text { (b) } \mathbf{W}^{*} \quad 2.6 \mathrm{~kJ} / \mathrm{mol} & 7.3 \mathrm{~kJ} / \mathrm{mol} \quad \text { ca. } 6 \mathrm{~kJ} / \mathrm{mol}\end{array}$
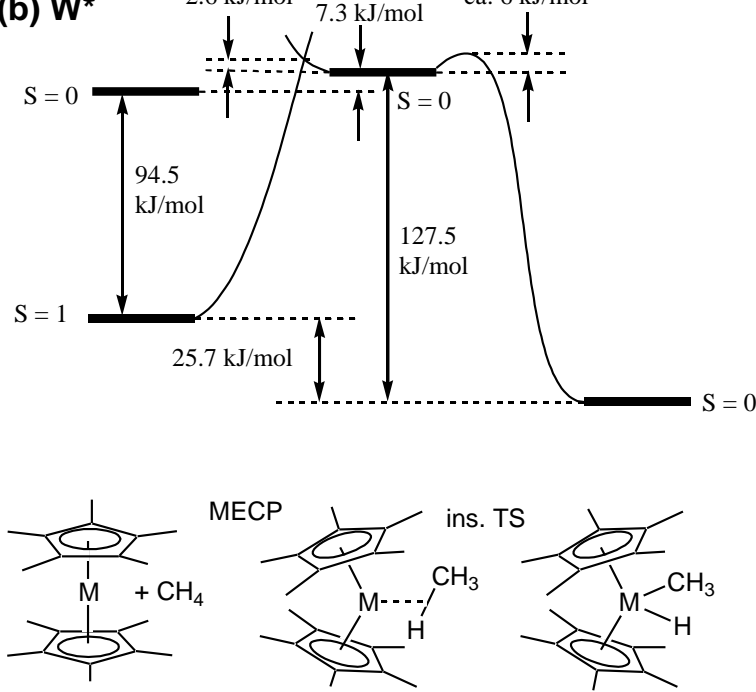